\title{
“A MONTEZUMA", POEMA DE ENGELBERT MVENG
}

\author{
Pablo Simpson ${ }^{1}$ \\ 1-Universidade Estadual Paulista “Júlio de Mesquita”, São José do Rio Preto, \\ São Paulo, Brasil
}

Resumo: O objetivo deste artigo é apresentar uma proposta de tradução do poema "A Montezuma" do poeta e teólogo camaronês Engelbert Mveng (1930-1995) e contextualizar, em seguida, dois aspectos da teologia de Mveng que se fazem notar no poema: o debate, por um lado, sobre a inculturação da mensagem católica no contexto africano, por outro, a ética cristã que Mveng faz recuar à compreensão das preces africanas como berço de um monoteísmo "transcendente e absoluto".

Palavras-chave: Engelbert Mveng; Poesia Africana; Teologia Cristã; Inculturação; Ritmo

\section{"A MONTEZUMA", POEM BY ENGELBERT MVENG}

\begin{abstract}
The aim of this article is to present a translation of the poem "A Monteczuma" by the Cameroonian poet and theologian Engelbert Mveng (1930-1995) as well as contextualize two aspects of his theology that could be noted in the poem: the debate, on the one hand, on the inculturation of the Catholic message in the African context, on the other, the Christian ethics that Mveng pushes back to the understanding of African prayers as the cradle of a "transcendent and absolute" monotheism.

Keywords: Engelbert Mveng; African Poetry; Christian Theology; Inculturation; Rhythm
\end{abstract}

\section{«A MONTEZUMA», POÈME DE ENGELBERT MVENG}

Resumé: L'objectif de cet article est présenter une proposition de traduction du poème "A Moteczuma" du poète et théologue camerounais 
Engelbert Mveng (1930-1995), aussi bien que contextualiser deux aspects de sa théologie qu'on pourrait bien noter dans le poème: d'une part, le débat sur l'inculturation du message catholique dans le contexte africain, d'autre part, l'éthique chrétienne que Mveng fait reculer à une compréhension des prières africaines comme berceau d'un monothéisme "transcendant et absolu".

Mots-clés: Engelbert Mveng; Poésie Africaine; Théologie Chrétienne; Inculturation; Rythme

\section{A Montezuma}

Para ti, Montezuma

Que és minha dupla América, Te envio a saudação da África

Para além da divisória líquida do Oceano

Entre nossos flancos de fraternidade.

Pois não és para mim mais do que o grande cemitério do juramento da amizade.

O cemitério de tuas raças,

De tuas dinastias,

De tantas civilizações degoladas em pleno meio-dia...

E nenhuma mulher em teu harém sobreviverá para o luto,

Nem carpideira no vento erguendo a floração de seus dez dedos,

Nem feiticeira para esconder os restos da Estátua,

Nem sacerdotisa

$\mathrm{Na}$ noite

Para trazer o incenso de mil gerações de prece,

E o único piscar de olhos,

Depois das luzes pulverizadas e das chamas apagadas,

Único piscar de teu olhar de chama!

Estás aqui

Deserto do pampa,

Solidão das florestas da Amazônia,

Estás aqui, 
Desde a Sierra Madre à cortante Cordilheira, Imensa necrópole e o vazio das pirâmides

Devorou a memória dos príncipes de Tula, E nenhum eco para além das fronteiras do passado

Dirá de novo o nome dos reis de Texcoco, E o clamor de seus exércitos mais forte que o ímpeto dos mares.

Estás aqui, formigueiro das tribos da fome, Minha América meridiana, Estás aqui desértica e repleta...

És para mim a panela do grande cozido de todos os povos reunidos,

Em teu seio,

És minha boca vulcânica escancarada ao flanco de nosso globo.

És minha dupla América desaparecida,

A dos Sioux, dos Abenaki, dos Assiniboine,

América dos Iroqueses,

Dos Incas,

Dos Chimimecas,

Grande cemitério do mundo

E que a chuva de minhas lágrimas

$\mathrm{Na}$ carne de tuas glebas chame o sangue vivo de povos novos.

Pois sou a saudação esponsal

Da África:

E digo:

Vale de Jeosafá

Sou a voz de Ezequiel

E semeio novas tribos!

No deserto dos arranhacéus de Washington, de Nova York, de Chicago,

Na selva do Sul despovoada pelos tigres,

Sou a serva do Senhor

Vendida ao mercador do Ocaso,

E minha voz canta e faço sóis se erguerem,

E meus suspiros são gota de orvalho na lama de seus ódios 
maculando minha veste virgem,

E estão todos prostrados,

E eu de pé,

Canto e domo o oceano,

Acalmo os tigres,

Eu falo,

E de seus cemitérios de prédios,

Ordeno que subam carnes vivas por seus esqueletos descarnados.

E tu és, Montezuma,

Meu pampa do meio-dia,

A Cordilheira da fome erguida em suas bacanais,

E eu, sou a África,

Na Bahia, no Rio de Janeiro,

Sou a África nas Antilhas,

Com minha veste em farrapos e meu grande riso solar,

$\mathrm{Na}$ carne de argila de teus cemitérios,

Sou seiva que sobe,

E tu és a folha de mostarda,

Meu irmão,

Amanhã seremos floração,

Amanhã, na ponta de nossos galhos pesados

em seus ninhos há de se cantar

a esperança.

\section{A Moteczuma}

A toi, Moteczuma

Qui est ma double Amérique, J'envoie le salut de l'Afrique,

Par-delà la cloison liquide de l'Océan

Entre nos flancs de fraternité.

Car tu n'es plus pour moi que le grand cimetière du serment de l'amitié.

Le cimetière de tes races, 
De tes dynasties,

De tant de civilisations égorgées en plein midi...

Et pas une femme en ton harem ne survivra pour le grand deuil,

Pas une pleureuse au vent déployant la frondaison de ses dix doigts,

Pas une sorcière pour cacher les débris de la Statue,

Pas une voix de prêtresse,

Dans la nuit,

Pour porter l'encens de mille générations de prière,

Et l'unique clignotement,

Après les lampadaires pulvérisés et les flambeaux éteints,

L'unique clignotement de ton regard de chandelle!

Et te voici

Désert de la pampe,

Solitudes des fôrets d'Amazonie,

Te voici,

Depuis la Sierra Madre jusqu'aux tranchants de la Cordillère,

Immense nécropole et le vide des pyramides

A dévoré la mémoire des princes de Tula

Et nul écho, par-delà les frontières du passé,

$\mathrm{Ne}$ redira le nom des rois de Texcoco,

Et la clameur de leurs armées plus puissante que le déferlement des flots.

Et te voici fourmilière des tribus de la faim,

Toi, mon Amérique méridienne,

Te voici, désertique et surpeuplée...

Et tu es pour moi la marmite du grand bouillon de tous les peuples rassemblés,

En ton sein,

Tu es ma bouche volcanique béante au flanc de notre globe.

Tu es ma double Amérique révolue,

Celle des Sioux, des Abnakis, des Assiniboéls,

Tu es l'Amérique des Iroquois, 
Des Incas,

Des Chichimèques,

Tu es le grand cimetière du monde

Et que la pluie des mes larmes,

Dans la chair de tes glèbes appelle le sang vif de peuples neufs.

Car je suis le salut sponsoral

De l'Afrique

Et je dis:

Vallée de Josaphat,

Je suis la voix d'Ezéchiel

Et je sème des tribus neuves!

Dans le désert des buildings de Washington, de New York, de Chicago,

Dans la jungle du Sud dépeuplée par les jaguars,

Je suis la servante du Seigneur

Vendue au marchand du Couchant,

Et ma voix chante et je fais lever les soleils,

Et mes sanglots sont goutte de rosée sur la boue de leur haine maculant mon pagne vierge,

Et tous sont prostrés,

Et moi je suis debout,

Je chante et je dompte l'océan,

Je domestique les jaguars,

Je parle,

Et de leur cimetières de buildings,

Je fais monter des chairs vives autour de leurs esquelettes décharnés.

E tu es, Moteczuma,

Ma pampa du midi,

Tu es la Cordillère de la faim dressée sur leurs bacchanales,

Et moi, je suis l'Afrique

A Bahia, a Rio de Janeiro,

Je suis l'Afrique aux Antilles,

Avec mon pagne en lambeaux et mon grand rire solaire,

Dans la chair d'argile de tes cimetières,

Je suis la sève qui monte 
Et tu es le sénevé,

Mon frère,

Demain nous serons frondaison de la saison,

Demain, au bout de nos branches alourdies,

Les couvées, dans leurs nids, chanteront l'espérance.

(Mveng 17-20)

Entre 2010 e 2012, vivi nos Camarões onde fui Leitor de Língua e Civilização brasileira na Université de Yaoundé. Nesse período, conheci a poesia de Engelbert Mveng (1930-1995) das mãos de meus alunos, que estudavam o seu livro Balafon, publicado em 1972, para as provas de acesso ao ensino superior. Em sua reedição de 2010 da Imprimerie Saint-Paul, de que provém o texto acima, é o que explica o dossiê pedagógico que percorre a trajetória de Mveng, poeta, artista e teólogo, cuja formação cristã no Seminário de St. Joseph d'Akono o conduziria ao Noviciado Jesuíta de Djuma, na República Democrática do Congo, em 1951, à Wépion, na Bélgica, entre 1954 e 1957, à Paris, ao Philosophat de Chantilly e ao Théologat de Fourvière, em Lyon, nos anos 1960, para ordenar-se padre jesuíta em 1963. Trata-se de uma trajetória por diferentes países que se pressente, no livro Balafon, no modo epistolar assumido por seus quatro poemas iniciais e na paisagem internacional evocada. O posfácio à edição, elaborado por Gilbert Doho e Marcelin Vounda Etoa, menciona ainda detalhes da luta anticolonial camaronesa a partir das greves de 1945 e a resposta de Mveng contra o que chamou de "holocausto colonial", com menção ao discurso que proferiu no momento das independências africanas em defesa de uma teologia da libertação, discurso publicado em Théologie, libération et cultures africaines, pelas editoras Présence Africaine e Editions Clé, em 1997, um dos centros para compreender o diálogo entre América Latina e África no poema “A Montezuma”. Engelbert Mveng, para quem o cristão deveria ser "um eterno contestador e 
um profeta", segundo Jean-Claude Djéréké, foi estrangulado em sua casa na aldeia Nkolfané, próxima à capital Yaoundé, em 23 de abril de 1995.

O poema "A Montezuma" lembra-nos da dicção de autores como Pablo Neruda, em "Las masacres" ou "Agonias" de seu Canto geral de 1950, e da forma do "verset" das Cinco grandes odes, de 1910, do poeta francês Paul Claudel, presente em autores da negritude como Léopold Sédar Senghor, segundo Michel Autrand. Propõe-nos ainda o diálogo com dois episódios do texto bíblico: com o Livro de Joel, no qual se indicam o vale de Jeosafá e a congregação de todos os povos; e com a parábola do grão de mostarda na pregação de Jesus no Evangelho de São Marcos, com que se opõem a pequenez do grão e as "folhas de mostarda"/sénevé já grandes, sob as quais os pássaros viriam fazer seus ninhos e cantar. É a mesma palavra que se repete noutro poema de Engelbert Mveng, intitulado "Pentecostes na África” (Mveng 63). Em ambos há o sentido de uma esperança que será a de uma voz capaz de falar a todos os povos. No texto do Evangelho de São Marcos, a continuação à parábola do grão de mostarda explicita o intuito de Jesus de adaptar-se - "anunciava-lhes a Palavra por meio de muitas parábolas como essas, conforme podiam entender" (MC 4-33) - em oposição à fala destinada aos apóstolos.

São dois aspectos da teologia de Mveng que a leitura desse poema, dedicado ao imperador asteca Montezuma, reencena. O primeiro deles, o desejo do eu de tornar-se, como no poema "Pentecostes na África", uma "semente matinal de toda língua da terra"/ "semence matutinale de toute langue sur la terre" (65), desejo de um Pentecostes com tam-tams, balafons, tambores, instrumentos corais de uma mensagem cristã ao povo africano. São conhecidos os estudos de Mveng, formado na Nova Teologia pré-Vaticano II, sobre a noção de inculturação. Em L'Art d'Afrique noire: liturgie cosmique et langage religieux, de 1964, aprofunda um debate já presente em sua tese de doutorado sobre Santo Agostinho, intitulada Paganisme et christianisme: christianisation de la civilisation païenne de l'Afrique romaine d'après la correspondance de saint 
Augustin. Pergunta-se sobre a possibilidade de Deus de "comunicar aos africanos" (Mveng 45) ou sobre a "encarnação do Verbo de Deus numa civilização humana, a civilização africana” (Mveng 45). A resposta será a mesma do poema: a celebração do canto, da música, dos ritmos, do simbolismo - simbólica e ritmo seriam duas "estruturas fundamentais de nossa arte" (Mveng 8) - na direção de uma mensagem de fraternidade universal. Considerar esse povo africano como destinatário da mensagem faz dele o eixo articulador da duplicidade central do poema, com sua dupla América, eixo que está na oposição entre a catástrofe colonial e sua desertificação humana, com cemitérios e necrópoles, a que se seguiriam povos novos. À desertificação da América corresponderia, assim, o povoamento africano, com suas tribos, com o sentido preciso de uma civilização cristã de homens novos. A África dos balafons, espécie de xilofone, instrumento harmônico-percusivo, é vista na perspectiva de seus ritmos, para pensar como Roger Bastide - “como já dissemos, a África é o ritmo, essa nova poesia vai dançar, girar, deslocar-se segundo ritmos antes desconhecidos" (Bastide 53) - mas também como lugar desse "homem novo".

Este é o segundo aspecto do poema "A Montezuma". Trata-se de pensar o lugar desse povo africano na mensagem cristã. Éloi Messi Metogo (5) afirmou que "o cristianismo está presente na África desde os tempos apostólicos”. Engelbert Mveng faz recuar esse diálogo às relações que identifica entre o mundo de Jesus e os egípcios. Vê na ética cristã da luta da vida contra as forças da morte uma herança africana que explicitará num conjunto de estudos, um deles intitulado "A Bíblia e a África negra”, de que extraio o seguinte fragmento:

Nós viemos de longe, do fundo da África, e vocês poderão ler nossos nomes em nossos rostos... Somos o povo dos crentes da África, o povo da Bíblia, o de que fala o profeta Isaías e que para além dos rios de Cuxe levará a Yahvé sua oferenda no Monte Sião, lá onde é adorado seu Nome... Viemos aprender a Sagrada Escritura, a mensagem da 
Bíblia, que é nossa mensagem, porque somos o povo da Bíblia, porque a África é a Terra da Bíblia e que o segundo rio do Paraíso se chama Géon e que ele cerca a terra de Cuxe, isto é, a África Negra. Desde o Gênesis, a África e os Africanos estão presentes na Bíblia; a mensagem da Bíblia é nossa mensagem e o Povo da Bíblia é nosso Povo. Nós também, nós somos herdeiros da Bíblia e responsáveis por sua mensagem ontem, hoje e amanhã. Viemos aprender a decifrar essa mensagem que é nossa tanto quanto de vocês. (Pocouta 33-34). ${ }^{1}$

Não temos condições de desdobrar aqui os lugares complexos dessa leitura, com sua menção ao Reino de Cuxe. Pauline Pocouta (34) evidenciou, por exemplo, como Mveng afasta-se da interpretação de Cuxe sob signo da maldição de Cam, compreendendo-a como posterior à Bíblia. Em L'Art d'Afrique noire: liturgie cosmique et langage religieux, situaria aí o berço de um monoteísmo "transcendente e absoluto" (Mveng 19). Traça não apenas um percurso que vai do cristianismo ao homem novo, vislumbrado nos povos africanos, porém identifica em formas de uma linguagem teologico-simbólica africana o caminho para a revelação cristã. Vê, por exemplo, num ornamento frequente às máscaras africanas a cruz inscrita num círculo: a cruz das quatro direções do mundo, o círculo da totalida-

\footnotetext{
1 "Nous sommes venus de loin, du fond de l'Afrique, et vous pouvez lire nos noms sur nos visages... Nous sommes le peuple des croyants d'Afrique, le peuple de la Bible, celui-là dont parle le prophète Isaïe et qui par-delà les fleuves de Kush apportera à Yahvé son offrande sur le Mont Sion, là où est adoré son Nom... Nous sommes venus apprendre l'Ecriture Sainte, le message de la Bible, qui est notre message, parce que nous sommes le peuple de la Bible, parce que l'Afrique est la Terre de la Bible et que le second fleuve du Paradis s'appelle Géon et qu'il entoure le pays de Kush, c'est-à-dire l'Afrique Noire. Depuis la Genèse, l'Afrique et les Africains noirs sont présents dans la Bible; le message de la Bible est notre message et le Peuple de la Bible est notre Peuple. Nous aussi, nous sommes les héritiers de la Bible et responsables de son message hier, aujourd'hui et demain. Nous sommes venus apprendre à déchiffrer ce message qui est notre message comme il est le vôtre." Tradução minha.
} 
de. Para afirmar que, por um lado, a catequese Banto poderá investir o signo da cruz de suas máscaras com as "riquezas da revelação cristã": "o iniciado africano que traz a símbolo do cosmos marcado pela cruz assume em liberdade a luta da vida e da morte" (30); por outro, que o africano já trazia consigo um projeto de homem religioso cuja visão de mundo se organizava num eixo dialético, opondo o aqui e o transcendente (6). A prece, que será o modo enunciativo de outros poemas de Balafon, traria, nesse sentido, uma estrutura marcada pela divisão entre a liberdade criadora e determinismo do mundo. $\mathrm{O}$ triunfo da liberdade preludiaria, "o triunfo da vida sobre a morte". É com ele, "grande riso solar", que conclui o poema "A Montezuma", com essa resposta ao sofrimento, a uma comunidade do sofrimento - dos judeus e africanos - para a qual o homem, afirma-nos, traria a linguagem da prece e da arte.

\section{Referências}

A Bíblia de Jerusalém. São Paulo: Paulus, 1980.

Autrand, Michel. "La négritude et son chant selon Claudel et Senghor." Revue d'histoire littéraire de la France, [s.1], vol. 88, no. 2, 1988, p. 185-200. Disponível em: <www.jstor.org/stable/40529219>. Acesso em: 26/09/2019.

Bastide, Roger. Poetas do Brasil. Prefácio de Antonio Candido, organização e notas de Augusto massi. São Paulo: Edusp/Duas cidades, 1997.

Djékéré, Jean-Claude. "Il y a 20 ans était assassiné Engelbert Mveng". Cameroonvoice, [s.1], avril 27, 2015. Disponível em: < https://cameroonvoice. com/opinion/2015/04/27/il-y-a-20-ans-etait-assassine-engelbert-mveng/ > . Acesso em:26/09/2019. 
Metogo, Éloi Messi et alli. "Cristianismos africanos". Concilium: Revistas internacional de Teologia, [s.1]. número 317, Petrópolis: Editora Vozes, 2006/4.

Mveng, Engelbert. Balafon, avec dossier pédagogique par Gilbert Doho et Marcelin Vounda Etoa. Yaoundé: Édition CLÉ, 2010.

Mveng, Engelbert. L'art d'Afrique noire: liturgie cosmique et langage religieux. Paris: Point Omega/Mame, 1964.

Pocouta, Paulin. "Engelbert Mveng: une lecture africaine de la Bible". Nouvelle Revue Théologique, [s.l], 120-1 (1998), p. 32-45. Disponível em: <https:// www.nrt.be/fr/articles/engelbert-mveng-une-lecture-africaine-de-la-bible-355 > . Acesso em: 26/09/2019.

Sagadou, Jean-Paul. "Saint Augustin et les païens/Engelbert Mveng et saint Augustin: Un Africain face à un 'Africain'”. Itinéraires Augustiniens $\mathrm{n}^{\circ} 38$ : Le chemin spirituel $>$ IV. Augustin aujourd'hui. Disponível em: < https:// www.assomption.org/fr/mediatheque/revue-itineraires-augustiniens/le-cheminspirituel/iv-augustin-aujourd-hui/saint-augustin-et-les-paiens-par-jean-paulsagadou > . Acesso em: 26/09/2019.

Recebido em: 03/10/2019 Aceito em: 20/11/2019 Publicado em dezembro de 2019

Pablo Simpson. E-mail: pablo.simpson@unesp.br ORCID: https://orcid.org/0000-0002-2645-8939 